\title{
Standalone photovoltaic array fed induction motor driven water pumping system
}

\author{
Atarsia Loubna ${ }^{1}$, Toufouti Riad ${ }^{2}$, Meziane Salima ${ }^{3}$ \\ ${ }^{1}$ Department of Electrical Engineering, Oum El Bouaghi University, Algeria \\ ${ }^{2,3}$ Department of Electrical Engineering, Laboratory of Electrical and Renewable Energies LEER, \\ Souk Ahras University, Algeria
}

\begin{tabular}{l} 
Article Info \\
\hline Article history: \\
Received Jun 16, 2019 \\
Revised Mar 4, 2020 \\
Accepted Mar 21, 2020 \\
\hline
\end{tabular}

\section{Keywords:}

Battery storage

Boost converter

Induction motor

MPPT PO

Solar photovoltaic array

Voltage source inverter

Water pump

\begin{abstract}
Due to the absence of energy transmission lines connected to the water pumping sites in remote areas, problems related to the electrical power outages and the environmental degradation caused by fossil fuel. For this one of the most conceived solutions is the photovoltaic water pumping technology which has the advantage of being sustainable and respectful of the environment to supply water to rural areas. To ensure the need of water, especially for domestic use and small communities, in this article, the photovoltaic energy system for autonomous water pumping using the induction motor was presented, particularly adapted to the isolated regions. Pumping system consists of four photovoltaic (PV) panels, boost converter, inverter, induction motor, centrifugal pump and a storage tank. In this study, the output power of a PV solar cell is fully used by proposing the $\mathrm{P} \& \mathrm{O}$ algorithm, where it is used to follow a maximum power point tracking (MPPT) technique. The recommended system is designed, modeled and simulated on the MATLAB / Simulink platform. The efficiency of the proposed algorithm is observed with variable solar sunshine.
\end{abstract}

Copyright (c) 2020 Institute of Advanced Engineering and Science. All rights reserved.

Corresponding Author:

Riad Toufouti,

Department of Electrical Engineering,

Souk Ahras University,

Annaba Road, 410001 Souk Ahras Algeria.

Email: riad.toufouti@univ-soukahras.dz

\section{INTRODUCTION}

The In the near future the world energy crisis is expected, due to the growing demand for electricity and the exhaustion of conventional sources, these main causes are due to the boom in industries and the population explosion [1, 2]. In addition, the consequences of these fossil fuels are quite obvious in the form of environmental pollution which distinguishes it from abrupt climate change and global warming. The extreme solution for these problems is the rise in advantage of renewable energy productions, So-called unconventional energy, worldwide. For this, researchers have oriented their research towards healthy and sustainable renewable energies for the future, such as solar, wind, geothermal, etc [2-4]. In this context several research works have been started in different research laboratories to exploit these resources. In [5] the authors have used the scalar command to control a dual-power asynchronous generator (GADA), for isolated regions using wind energy, simulation and experimental results in the face of variations in wind speed have shown that the application of GADA gives good performance. In [6] the authors presented an experimental study on vector control. It is efficient for optimizing the energy production of a wind turbine conversion chain based on the hexaphase asynchronous generator. In the article [7] a pumping system is presented using wind energy (WECS), an SPV array and a battery.

Knowing that water is a vital availability and to reduce monsoon dependence in rural areas. The pumping of water has become a necessary need in everyday life $[8,9]$, pumping water using the solar 
system can give substantial results and satisfy the demands of irrigation in agriculture, use for domestic purposes, to livestock and for industrial use. The use of solar energy is an interesting application for standalone power generation system [8, 10, 11]. Efforts are underway to exploit solar energy for pumping $[8,12,13]$. In [14], the authors presented an in-depth study of a pumping system powered by the PV solar system, by developing the MATLAB Simulink model of the complete system .

In [15] the authors treat a pumping system driven by a brushless DC motor (BLDC) powered by the PV solar system and an accumulator. Using the SPV battery-based hybrid generation as an energy source. Simulation study was done by developing the Matlab / Simulink model of the complete system.

In our article we are interested in photovoltaic solar energy (PVP) which takes the lead of unconventional energy sources [2,8]. Because it has many advantages, simple and consistent installation, availability, low protection, no energy and transport costs, robustness, unattended procedure [4, 16]. In this context several research projects have been started, in [17] the authors have exploited the photovoltaic generator at the MPPT by means of a DC/DC boost converter. Among the many MPPT algorithms, the P\&O MPPT technique is the most used because of its good competency to variations in sunlight as evidenced by the simulation results under Matlab / Simulink in the article.

The second part of our work presents the modeling of the different elements of the solar pumping system such as the photovoltaic panel, boost converter, induction motor and the centrifugal pump. The third section presents the photovoltaic generator in operation at the point of maximum power (MPPT), hence the architecture of the proposed MPPT, as well as the basic modeling necessary to the understanding of its principle of operation. The results are treated in the MATLAB/Simulink environment for the solar pumping system in order to study the performances in steady and dynamic regime are reported in sections 4 . The conclusions and concluding remarks are reported in section 5.

\section{STRUCTURE OF SYSTEM}

\subsection{Configuration of the proposed system}

In the following Figure 1 present the solar pumping system studied in this article, which consists of the photovoltaic generator PVG, power converters (Boost converter and DC-AC converter), induction motor and centrifugal pump [18]. This part includes the modeling of the different elements of the solar pumping system such as the photovoltaic panel PV, the induction motor and the centrifugal pump.

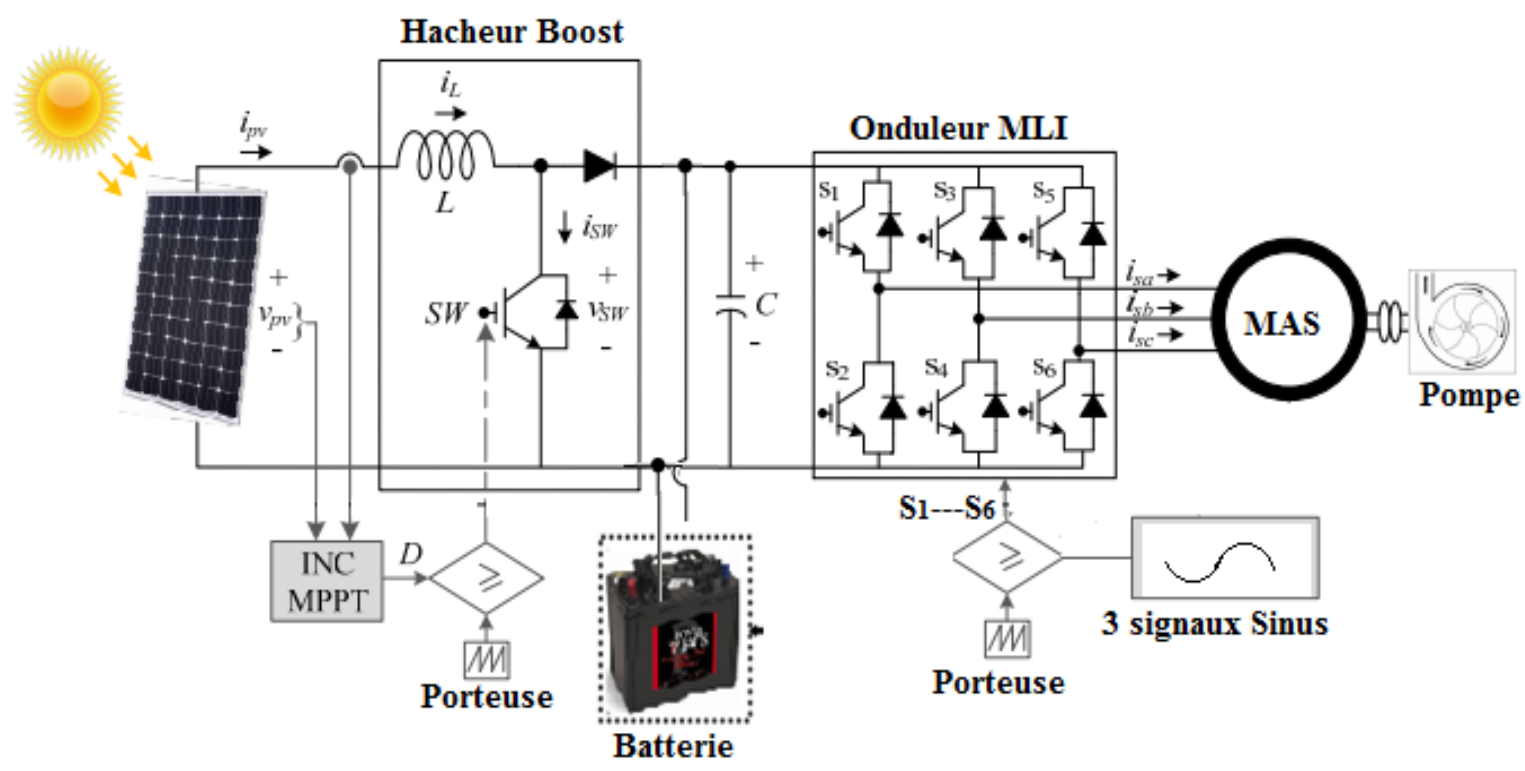

Figure 1. Synoptic structure of photovoltaic water pumping

\subsection{Modeling of photovoltaic generator}

The photovoltaic generator is used to produce electricity from sunlight, the generation of the energy supplied to the boost converter, which helps to operate the PV array to the MPPT. This converter then supplies energy to the induction motor which is coupled to the water pump [19,20]. The modeling of the photovoltaic 
device can be given by the equivalent circuit illustrated in Figure 2. which consists of a current source connected in parallel with diode according with shunt includes a parallel resistor (Rsh) expressing a leakage current, and series resistor noted by (Rsh) and (Rse) describing an internal resistance [18, 20].

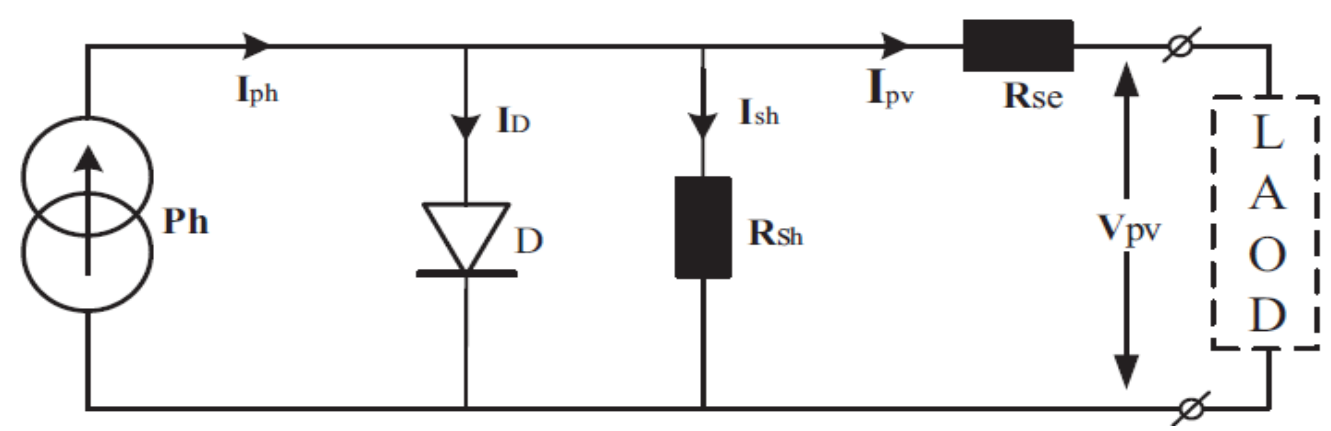

Figure 2. Photovoltaic array circuit

The photovoltaic module has non-linear characteristics (V\&I) and depends on the solar radiation and the temperature of the cells [21]. Equation (1) present the relationship of the output voltage-current [18, 21]:

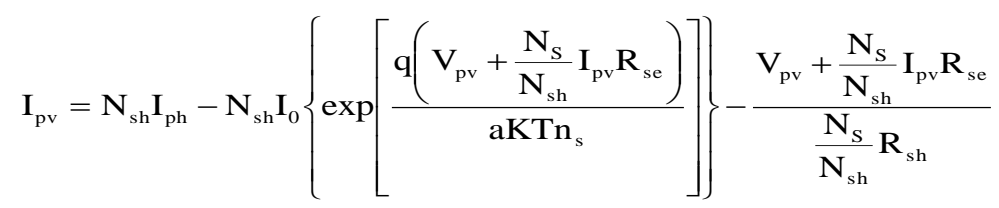

where, the reverse saturation current of the cells depends to the temperature (T) as follows:

$$
I_{0}=I_{o r}\left(\frac{T}{T_{r}}\right)^{3} \exp \left\{\frac{q E_{G}}{K_{a}}\left[\frac{q E_{G}}{K_{a}}-\frac{1}{T}\right]\right\}
$$

In addition, solar radiation $(\mathrm{G})$ and cell temperature $(\mathrm{T})$ have a direct relationship on the photocurrent Iph as follows:

$$
\mathrm{I}_{\mathrm{ph}}=\left\{\mathrm{I}_{\mathrm{scr}}+\mathrm{K}_{\mathrm{i}}(\mathrm{T}-298)\right\} \frac{\mathrm{G}}{\mathrm{G}_{\mathrm{r}}}
$$

where:

$I_{p h}$ and $I_{d}$ : are respectively the photocurrent and the junction diode current.

$I_{0} \quad:$ is the reverse saturation current, $V_{t}=N_{s} k_{t} / q$ : is the thermal voltage of the array with $N_{s}$ cells connected in series.

$A \quad:$ is the diode ideality constant, $k$ : is the Boltzmann's constant, $T[K]$ : Temperature of the p-n junction.

$k[J / K]:$ Boltzmann constant, $q[C]$ : Electron charge.

\subsection{Boost converter}

To improve the performance of the photovoltaic system. a power converter is inserted between the photovoltaic generator and the load [20], this generator is supplied by the DC-DC voltage converter "Boost", see Figure 3, where the output voltage of the PVG is ensured from the algorithms maximum power point tracker MPPT which depends on climatic conditions $[18,20]$

The following relation presents the output voltage (Vdc):

$$
\mathrm{V}_{\mathrm{dc}}=\frac{1}{1-\alpha} \mathrm{V}_{\mathrm{pv}}
$$


Also:

$$
\mathbf{I}_{\mathrm{dc}}=(1-\alpha) \mathbf{I}_{\mathrm{pv}}
$$

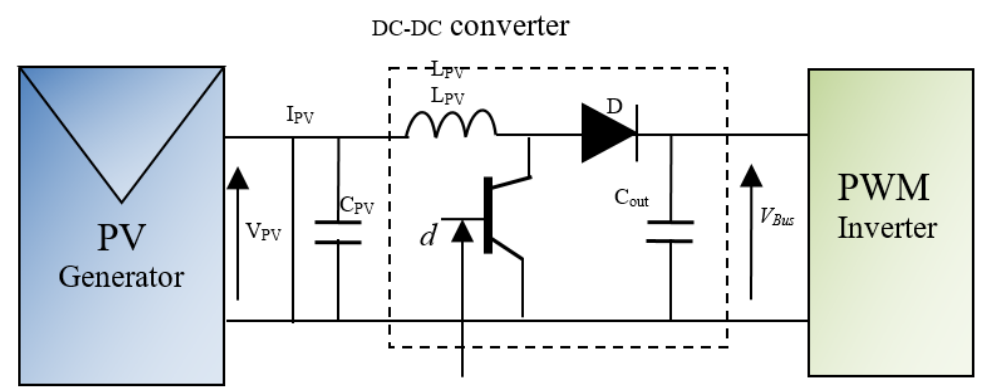

Figure 3. Diagram of the boost converter

\subsection{Induction motors modèle}

Three-phase induction motors were chosen for our study because of their broad advantages, such as robust construction, good speed regulation and high power factor [22]. The model of the IM in a coordinate system $(\mathrm{d}, \mathrm{q})$ connected to the rotating field synchronous at the speed is given as follow [23, 24]:

$$
\dot{x}=f(x)+g(x) \cdot u
$$

With: $x=\left[\begin{array}{lllll}I_{s d} & I_{s q} & \phi_{r d} & \phi_{r q} & \Omega\end{array}\right]^{T} u=\left[\begin{array}{ll}u_{s d} & u_{s q}\end{array}\right]^{T}$

$$
f(x)=\left[\begin{array}{c}
-\gamma I_{s d}+\frac{K}{T_{r}} \phi_{r d}+p \Omega K \phi_{r q} \\
-\gamma I_{s q}-p \Omega K \phi_{r d}+\frac{K}{T_{r}} \phi_{r q} \\
\frac{M}{T_{r}} I_{s d}-\frac{1}{T_{r}} \phi_{r d}-p \Omega \phi_{r q} \\
\frac{M}{T_{r}} I_{s q}+p \Omega \phi_{r d}-\frac{1}{T_{r}} \phi_{r q} \\
p \frac{M}{J L_{r}}\left(\phi_{r d} I_{s q}-\phi_{r q} I_{s d}\right)-\frac{1}{J}\left(T_{L}+f\right)
\end{array}\right][g]=\left[\begin{array}{l}
g_{1} \\
g_{2}
\end{array}\right]^{T}=\left[\begin{array}{ccccc}
\frac{1}{\sigma L_{S}} & 0 & 0 & 0 & 0 \\
0 & \frac{1}{\sigma L_{s}} & 0 & 0 & 0
\end{array}\right]^{T}
$$

With rotor and stator times constant are:

$$
T_{r}=\frac{L_{r}}{R_{r}} ; T_{s}=\frac{L_{s}}{R_{s}}
$$

The coefficient of dispersion is: $\sigma=1-\frac{M^{2}}{L_{r} L_{s}}$ and $\gamma=\left[\frac{1}{\sigma \cdot T_{s}}+\frac{1}{T_{r}} \cdot\left(\frac{1-\sigma}{\sigma}\right)\right] ; K=\left[\frac{1-\sigma}{M \cdot \sigma}\right]$

Then the expression of the electromagnetic couple will be as follows [7]:

$$
\begin{gathered}
T_{e m}=\frac{P M}{L_{r}}\left(\phi_{r d} I_{s q}-\phi_{r q} I_{r d}\right) \\
J \frac{d \Omega_{r}}{d t}=T_{e m}-T_{L}-f \Omega_{r}
\end{gathered}
$$




\subsection{Centrifigual pump}

The important part of photovoltaic water pumping systems is the hydraulic pump [21]. and the most commonly used type of pumping technology is the centrifugal pump, because it simple worked, flexible modular1, relatively high efficiency and capable of pumping a high volume of water $[18,20]$.

$$
H_{\text {pump }}=k_{o}+k_{1} Q+k_{2} Q^{2}
$$

Where

$k 0, k 1, k 2 \quad:$ are the constant of the pump,

$\mathrm{H}[\mathrm{m}]$ and $\mathrm{Q}[\mathrm{L} / \mathrm{s}]$ : are respectively, the head and the flow rate of the pump $[25,26]$.

The centrifugal pump is mechanically coupled to the induction motor, where it presents the mechanical load of this IM motor [21]. The mechanical equation of the system is given by the following expression [22]:

$$
J \frac{d \Omega}{d t}=T_{e m}-T_{p u m p}
$$

Using the torque-speed relationship, the centrifugal pump can be presented as follows:

$$
T_{\text {pump }}=k_{T O}+k_{T 1} \Omega+k_{T 2} \Omega^{2}
$$

where, $k_{T 0}, k_{T 1}, k_{T 2}$ the empirical constants of the pump that can be obtained from the measurements

\section{OPTIMIZATION OF THE PHOTOVOLTAIC WATER PUMPING SYSTEM}

The model of PV system P\&O control of DC-DC boost converter is shown in Figure 4. The level of insulation and the operating temperature have a strong relationship and depend on the maximum power that can be supplied by a PV panel. Therefore, the MPP must be followed all the time. Because this method has the advantage of being robust and relatively simple to design where it does not require knowing the exact model [18]. The P\&O technique is one of the simplest and most popular techniques of MPPT. It requires few mathematical calculations that make the implementation of this algorithm quite simple [21]. The paramount idea of this method is to push the system to operate in the direction where the output power supplied from the PV system boost up [22].

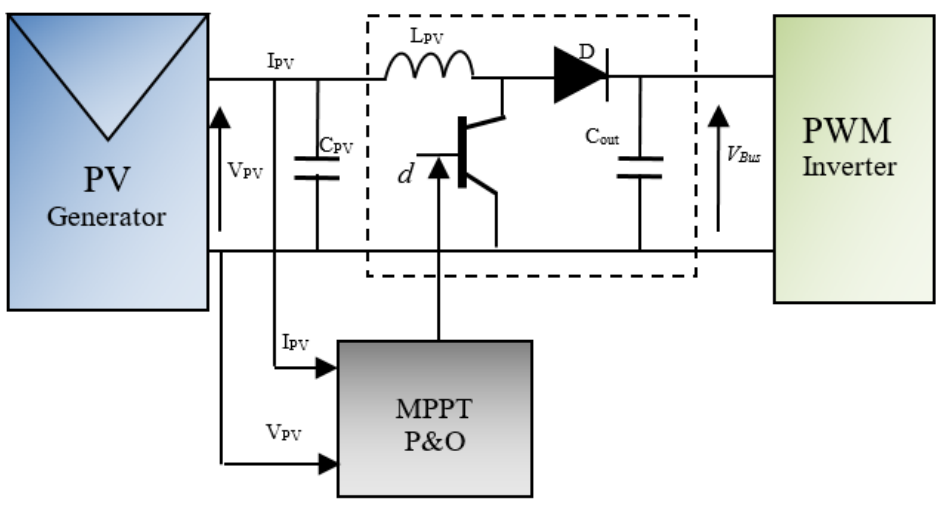

Figure 4. PV system P\&O control of DC-DC boost converter

Consequently, the perturbation and observation method $(\mathrm{P} \& \mathrm{O})$ increments/decreases periodically, due to the comparison of the panel voltage (PV output power) and that of the previous cycle [27]. In this disturbance leads to an increase/decrease in the power of the module, this disturbance occurs in the same/opposite direction. Variations in voltage and output power before and after the changes are then observed and compared to be the benchmark for increasing or decreasing the load in the next step. For better 
clarification the following diagram clearly shows what corresponds to the algorithm implemented [20], see Figure 5.

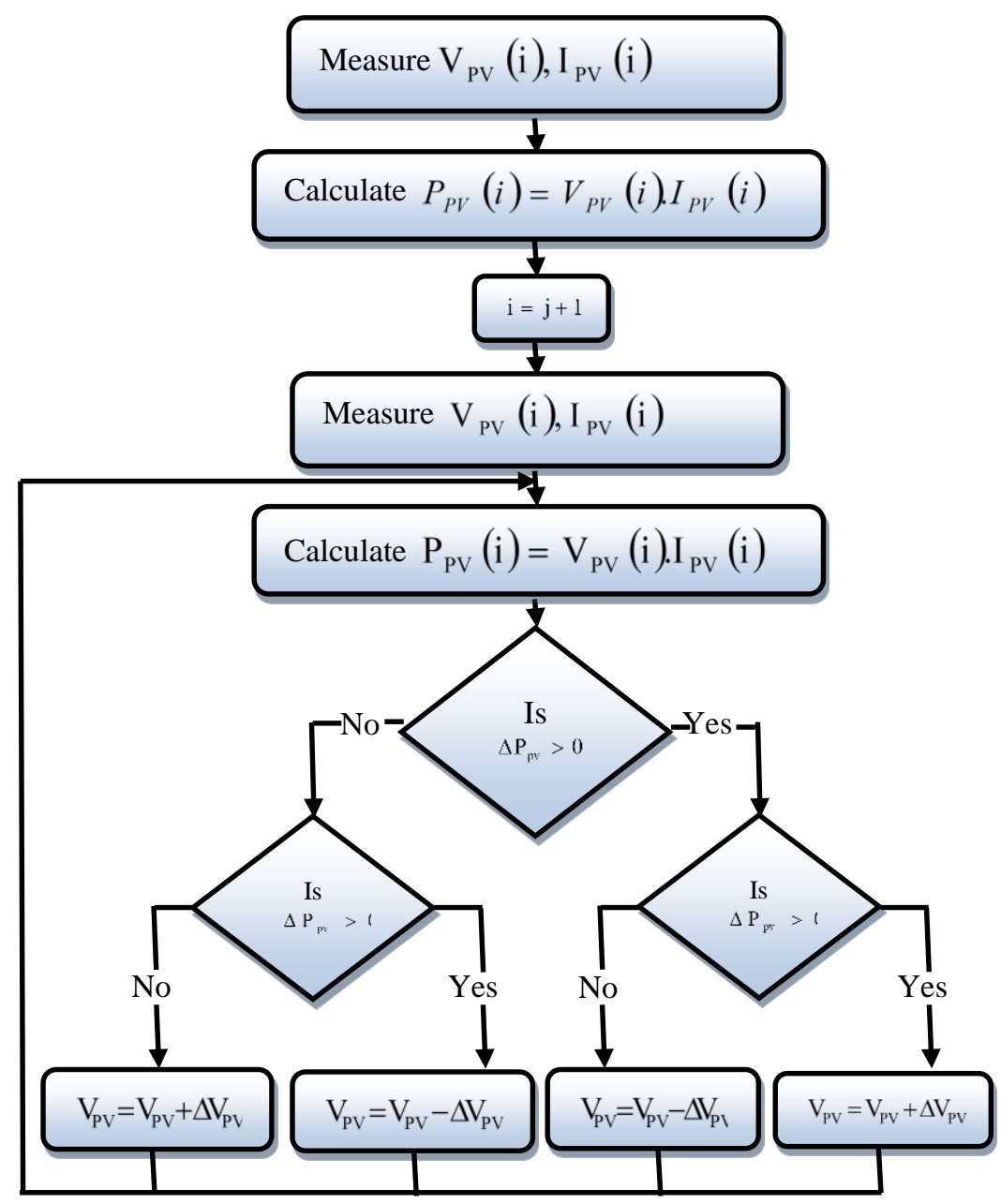

Figure 5. Flowchart of PO MPPT algorithm

\section{SIMULATION RESULTS}

The proposed PV water pumping system is illustrated in Matlab by the following Figure 6 . The proposed pumping system is modeled and simulated under MATLAB/Simulink under various conditions, in start-up, in steady state and for other dynamics.

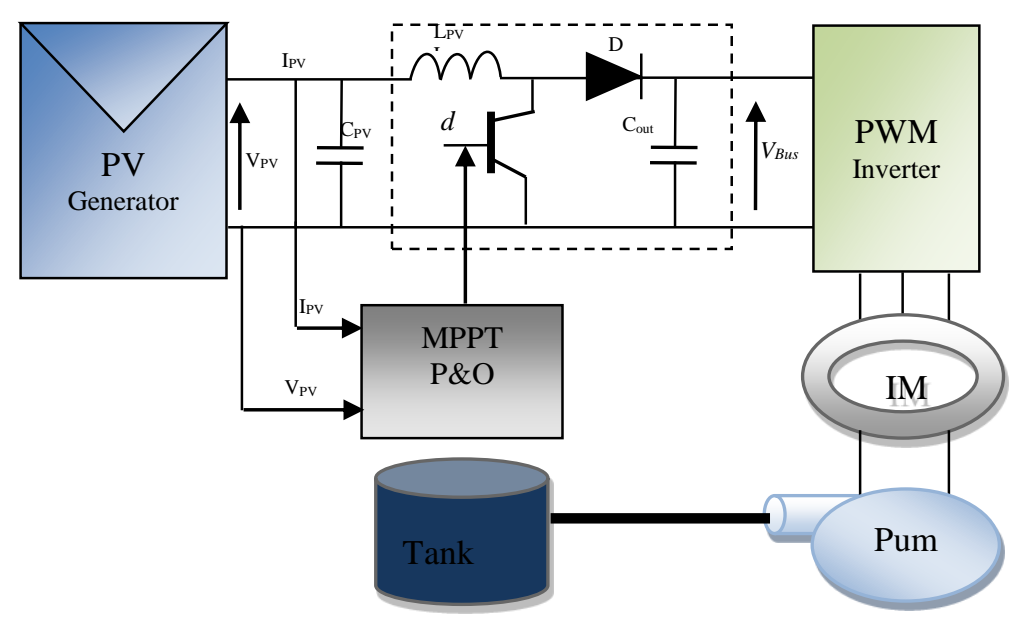


Figure 6. The simulation bloc of system

Figures 7 and 8 respectively show the variations in insolation and the DC voltage at the output of the photovoltaic panel. The manometric height is well maintained for the variation of the temperature that that obtained for a variation of the sunshine see Figure 9. From Figure 10, we notice that the pump has not debited from the water after reaching a certain speed value of the MAS. Figure 11, shows good rotor speed responses in steady state and is not affected by the changes of insolation. Figure 12 shows good responses of electromagnetic and pump torques in steady state. We can observe that the torque reaches its reference with very fast dynamic. Figure 13 shows the phase stator current. Figure 14 present the voltage of inverter.

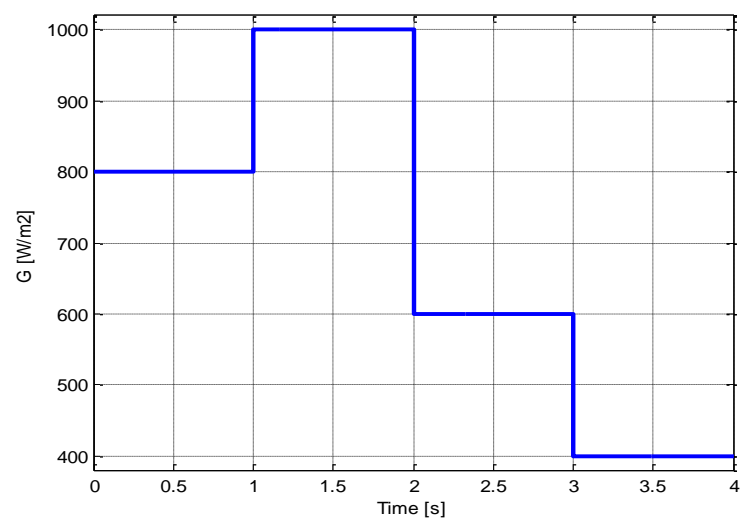

Figure 7. Variation of the insolation

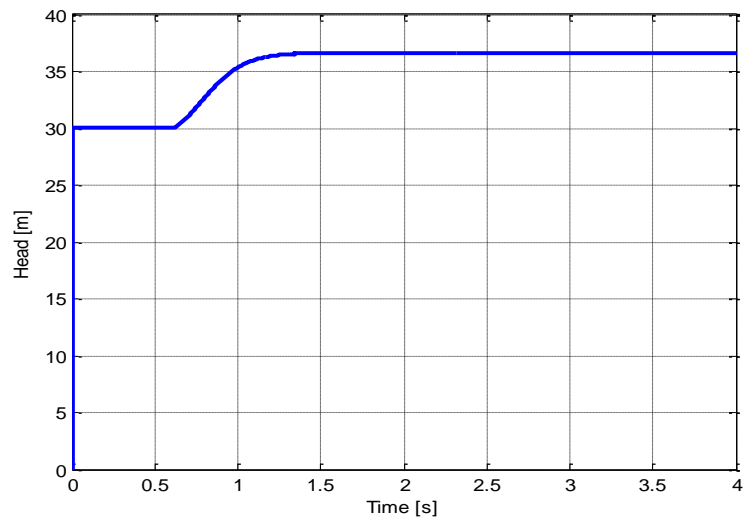

Figure 9. Total head monomeric

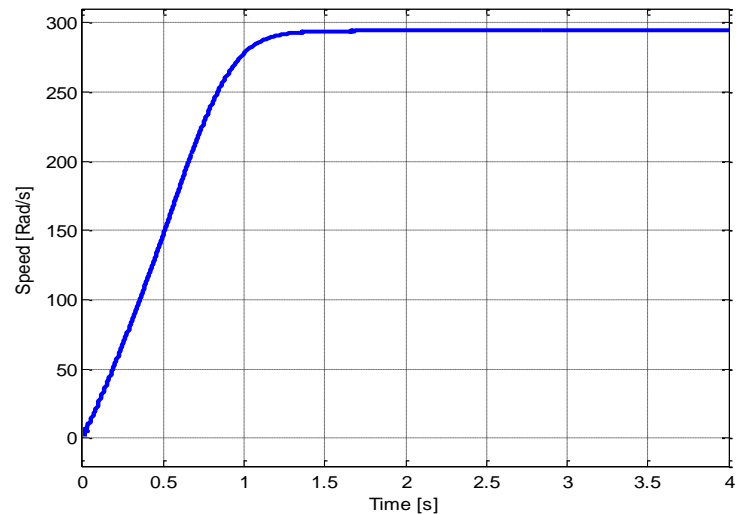

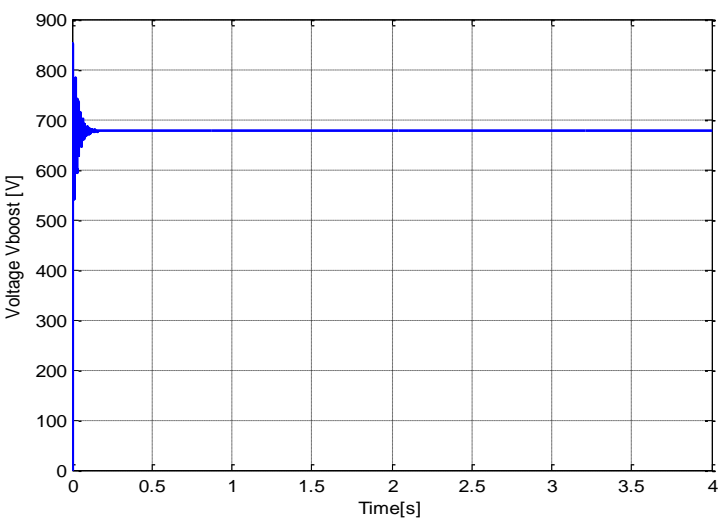

Figure 8. Output DC voltage of Pv panel

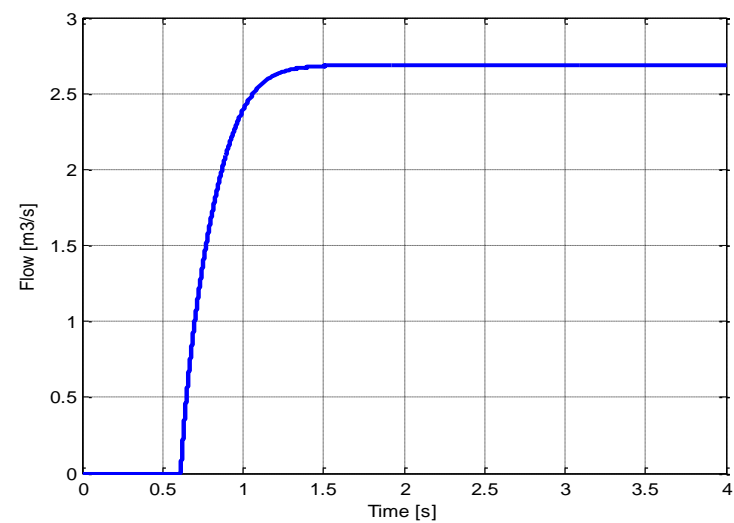

Figure 10. Flow rate

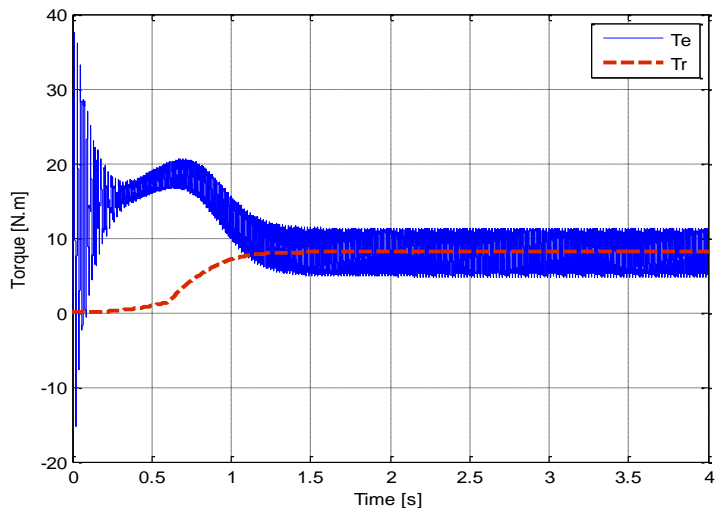


Figure 11. Rotor speed

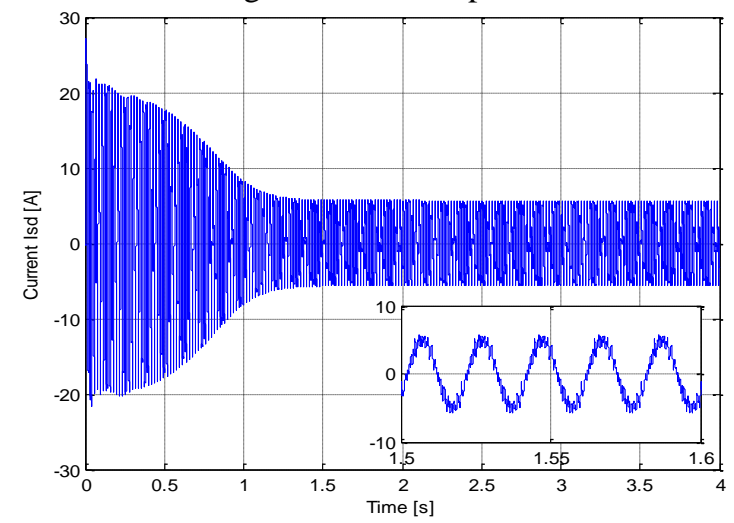

Figure 13. Phase stator current
Figure 12. Electromagnetic and pump torques

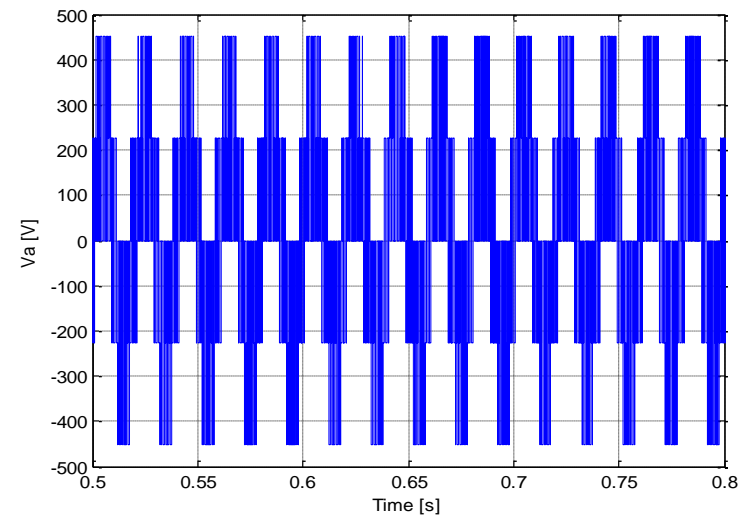

Figure 14. Voltage of inverter (zoom)

\section{CONCLUSION}

In this work, we have presented the modeling of a water pumping system; based on renewable energy in our case the photovoltaic solar energy (PVP). a stand-alone photovoltaic powered water pumping system using induction motor drive, especially suited for usage in rural or remote areas. From the simulation results obtained we note that the integration of the MPPT, allowed us to operate our pumping system even in the presence of fluctuations in metrological conditions, because the photovoltaic generator operates at its maximum power because the MPPT algorithm performs its role correctly for the search of the maximum point of the power, where the point of maximum power moves to reach the new maximum point corresponding to this new insolation or temperature.

\section{REFERENCES}

[1] R. Kumar and B. Singh, "Single stage solar PV fed brushless DC motor driven water pump," IEEE Journal of Emerging and Selected Topics in Power Electronics, vol. 5, pp. 1377-1385, 2017.

[2] B. Singh and S. Shukla, "Induction motor drive for PV water pumping with reduced sensors," IET Power Electronics, vol. 11, pp. 1903-1913, 2018.

[3] G. Dadhich and V. Shrivastava, "Economic comparison of solar PV and diesel water pumping system," in 2017 International Conference on Information, Communication, Instrumentation and Control (ICICIC), pp. 1-6, 2017.

[4] A. Varshney and B. Singh, "Direct torque controlled synchronous reluctance motor drive for PV array fed water pumping," in 2018 IEEMA Engineer Infinite Conference (eTechNxT), pp. 1-6, 2018.

[5] S. Drid, M.-S. Nait-Said, and A. Makouf, "Regular paper Doubly Fed Induction Generator Modeling and Scalar Controlled for Supplying an Isolated Site," J. Electrical Systems, vol. 2, pp. 103-115, 2006.

[6] A. Pantea, A. Sivert, A. Yazidi, F. Betin, S. Carriere, and G.-A. Capolino, "Efficient field oriented control with power losses optimisation of a six-phase induction generator for wind turbines," in IECON 2016-42nd Annual Conference of the IEEE Industrial Electronics Society, pp. 1912-1917, 2016.

[7] A. Kumar, E. Kochhar, and K. Upamanyu, "Photovoltaic and wind energy hybrid sourced voltage based indirect vector controlled drive for Water Pumping System," in 2015 IEEE International Conference on Electrical, Computer and Communication Technologies (ICECCT), pp. 1-5, 2015.

[8] U. Sharma, B. Singh, and S. Kumar, "Intelligent grid interfaced solar water pumping system," IET Renewable Power Generation, vol. 11, pp. 614-624, 2016.

[9] M. C. Morani, A. Carravetta, G. Del Giudice, A. McNabola, and O. Fecarotta, "A comparison of energy recovery by PATs against direct variable speed pumping in water distribution networks," Fluids, vol. 3, no. 2, pp. 41, 2018.

[10] R. Kumar and B. Singh, "BLDC motor-driven solar PV array-fed water pumping system employing zeta converter," IEEE Transactions on Industry Applications, vol. 52, pp. 2315-2322, 2016.

[11] R. Kumari and R. Dahiya, "Speed control of solar water pumping with indirect vector control technique," in 2018 2nd International Conference on Inventive Systems and Control (ICISC), pp. 1401-1406, 2018.

[12] S. Jain, R. Karampuri, and V. Somasekhar, "An integrated control algorithm for a single-stage PV pumping system using an open-end winding induction motor," IEEE Transactions on Industrial Electronics, vol. 63, pp. 956-965, 2015 .

[13] M. Kolhe, J. Joshi, and D. Kothari, "Performance analysis of a directly coupled photovoltaic water-pumping system," IEEE Transactions on Energy Conversion, vol. 19, pp. 613-618, 2004.

[14] B. Kumar, Y. K. Chauhan, and V. Shrivastava, "Performance analysis of a water pumping system supplied by a photovoltaic generator with different maximum power point tracking techniques," Songklanakarin Journal of Science \& Technology, vol. 36, no. 1, pp. 107-113, 2014. 
[15] R. Kumar and B. Singh, "Solar PV-battery based hybrid water pumping system using BLDC motor drive," in 2016 IEEE 1st International Conference on Power Electronics, Intelligent Control and Energy Systems (ICPEICES), pp. 1-6, 2016.

[16] V. Khare, S. Nema, and P. Baredar, "Solar-wind hybrid renewable energy system: A review," Renewable and Sustainable Energy Reviews, vol. 58, pp. 23-33, 2016.

[17] R. Antonello, M. Carraro, A. Costabeber, F. Tinazzi, and M. Zigliotto, "Energy-efficient autonomous solar waterpumping system for permanent-magnet synchronous motors," IEEE Transactions on Industrial Electronics, vol. 64, pp. 43-51, 2017.

[18] H. Bouzeria, C. Fetha, T. Bahi, I. Abadlia, Z. Layate, and S. Lekhchine, "Fuzzy logic space vector direct torque control of PMSM for photovoltaic water pumping system," Energy Procedia, vol. 74, pp. 760-771, 2015.

[19] M. Kashif, S. Murshid, and B. Singh, "Standalone solar PV array fed SMC based PMSM driven water pumping system," in 2018 IEEMA Engineer Infinite Conference (eTechNxT), pp. 1-6. 2018.

[20] S. Jaziri and K. Jemli, "Optimization of a photovoltaic powered water pumping system," in 2013 International Conference on Control, Decision and Information Technologies (CoDIT), pp. 422-428, 2013.

[21] M. Salima, A. Loubna, and T. Riad, "A Global Stability of Linearizing Control of Induction Motor for PV Water Pumping Application," International Journal of System Dynamics Applications (IJSDA), vol. 7, pp. 31-56, 2018.

[22] G. Jain and S. Umashankar, "Modelling and simulation of solar photovoltaic fed induction motor for water pumping application using perturb and observer MPPT algorithm," in 2016 International Conference on Energy Efficient Technologies for Sustainability (ICEETS), pp. 250-254, 2016.

[23] L. Atarsia, A. Oukaci, R. Toufouti, and S. Meziane, "Direct Torque Control Of Induction Motor And Regulation Speed Using The Adaptive Control." International Conference on Automatic control, Telecommunications and Signals (ICATS15), pp. 1-7, 2015.

[24] M. Moutchou and H. Mahmoudi, "Sensorless exact input-output linearization control of the induction machine, based on parallel stator resistance and speed mras observer, with a flux sliding mode observer," International Journal on Electrical Engineering and Informatics, vol. 6, no. 2, pp. 324-341, 2014.

[25] M. Belarbi, "'Modélisation et Simulation d'un Système de Pompage Photovoltaïque'," Mémoire de Magister Université des Sciences et de la Technologie d'Oran Mohamed BOUDIAF, 2006.

[26] R. Karampuri, S. Jain, and V. Somasekhar, "A single-stage solar PV power fed Open-End Winding Induction Motor pump drive with MPPT," in 2014 IEEE International Conference on Power Electronics, Drives and Energy Systems (PEDES), pp. 1-6, 2014.

[27] A. Mohapatra, B. Nayak, P. Das, and K. B. Mohanty, "A review on MPPT techniques of PV system under partial shading condition," Renewable and Sustainable Energy Reviews, vol. 80, pp. 854-867, 2017. 